\title{
SUBSTÂNCIAS FARMACOLÓGICAS E O DOPING ESPORTIVO
}

\author{
Jhonny Carlos Mateini Segatti \\ Graduado em educação física /FAMMA \\ jhonnysegatti@outlook.com
}

Daniel Vicentini de Oliveira

Doutorando em Gerontologia /UNICAMP

d.vicentini@hotmail.com

\author{
Mateus Dias Antunes \\ Mestrando em Promoção de Saúde/UNICESUMAR \\ mateus_antunes03@hotmail.com
}

Daniel Eduardo da Cunha Leme

Mestrando em Gerontologia/UNICAMP

daniel.eduardo.7@hotmail.com

\author{
Weslei Jacob \\ Doutorando em Atividade física, educação física e esporte / UB \\ wesleyjacob@bol.com.br
}

\section{RESUMO}

Determinadas substâncias farmacológicas são vendidas sem restrições e podem ser detectadas em exames antidopagem. O objetivo do presente estudo foi realizar uma revisão de literatura sobre as substâncias farmacológicas de fácil acesso, que podem causar o doping esportivo. Foi realizada pesquisa de artigos científicos em bases de dados, livros e dissertações publicados na área. Verificou-se que a hidroclorotiazida, espironolactona, terbutalina e salbutamol são substâncias comumente utilizadas por atletas das modalidades de luta, para a perda de líquido, na manutenção do peso corporal e broncodilatadores por corredores e nadadores, para a broncodilatação de vias aéreas superiores, a fim de melhorar o rendimento em competições. Tais medicamentos são comercializados livremente em redes de farmácias, sendo considerados doping esportivo. Conclui-se que, dentre as substâncias responsáveis pelo doping, as mais utilizadas são os estimulantes, analgésicos, diuréticos e antidiarreicos e que esses medicamentos estão de fácil acesso nas farmácias para o consumo da sociedade, inclusive os atletas.

Palavras-chave: Esporte; Doping; Alto rendimento.

\begin{abstract}
Certain drug substances are sold without restrictions and can be detected in doping tests. The aim of this study was to conduct a literature review of the pharmacological substances easily accessible, which can cause the sports doping. scientific articles survey was conducted in databases, books and dissertations published in the area. It was found that hydrochlorothiazide, spironolactone, terbutaline and albuterol are substances commonly used by athletes of modalities of struggle, for fluid loss, maintenance of body weight and bronchodilators for runners and swimmers, for bronchodilation upper airway, improve the performance competitions. Such drugs are sold freely in pharmacies networks, are considered sports doping. In conclusion, the substances responsible for doping, the most used are stimulants, analgesics, diuretics and antidiarrheal and that these drugs are easily accessible in pharmacies for the consumption of society, including athletes.
\end{abstract}

Keywords: Sport; Doping; High yield. 


\section{INTRODUÇÃO}

A palavra "doping" foi acrescentada em um dicionário inglês no ano de 1889, sendo definida como a mistura de ópio e narcóticos em cavalos (WEINECK, 2005). Em uma retrospectiva histórica, o doping era comum no período romano, época em que houve o aumento do prestígio pelos esportes, e consequentemente, havia a utilização de substâncias nos cavalos, para que corressem mais e nos gladiadores, a fim de aumentar a força e a violência nos combates. Outros relatos foram observados nas diferentes épocas, desde Grécia antiga (300 a.c) às últimas décadas, principalmente nos jogos olímpicos, ganhando gerações em várias modalidades esportivas (AQUINO NETO, 2001).

Em 1993, a Federação Internacional de Medicina Esportiva (FIMS) em um documento publicou que o "doping nos esportes é o uso proposital ou não intencional por um atleta de uma substância ou método proibidos pelo Comitê Olímpico Internacional (COI)" (PRECIADO, 2008).

O doping é considerado nos dias de hoje o uso de substancias ou métodos capazes de aumentar artificialmente o desempenho esportivo e que estejam listados pela World Anti-Doping Agency/ International Olympic Committee (WADA-AM/IOC) sejam eles porencialmente prejudiciais á saúde do atleta ou a de seus adversários, ou contrpario ao espírito do jogo (SILVA; MARCELINO. GONZALEZ, 2013).

Algumas substâncias são comercializadas livremente e podem causar melhoria no rendimento do atleta, tais como: a hidroclorotiazida, manitol, espironolactona, clortalidona, salbutamol e terbutalina. Todas elas são vendidas sem nenhuma restrição e podem ocasionar o doping esportivo (WEINECK, 2005).

Existe alguns medicamentos ou substâncias que podem ser de vendidos com livre acesso em estabelecimentos farmacêuticos e/ou os prescritos por médicos e que poderão ser acusados no exame antidoping, que de acordo com a quantidade e a reincidência administrada, pode levar o atleta usuário a uma punição ou expulsão e até mesmo a desclassificação (FIGUEIREDO et al., 2011; MARTINS et al., 2013).

Nesse sentido, o presente estudo visou responder a seguinte questão norteadora: Quais medicamentos de fácil acesso podem conter substâncias que causam o doping esportivo? Este artigo teve como objetivo verificar, por meio de uma revisão de literatura, as substâncias farmacológicas de fácil acesso que podem causar o doping esportivo.

\section{METODOLOGIA}

Para o desenvolvimento do presente estudo foi realizado uma pesquisa bibliográfica nos anos de 2000 a 2016 por meio de buscas em periódicos nacionais e internacionais indexados nas bases de dados Scielo, Lilacs e Medline e livros didáticos. Os descritores utilizados foram: Doping nos Esportes, Atividade Física, Fármacos, Ações Farmacológicas e Promoção da Saúde escritas no idioma português, espanhol e inglês. O período de busca foi entre os meses de janeiro a junho de 2016 e após selecionar os artigos, para extrair as definições sobre o tema procedeu-se à leitura dos mesmos.

\section{RESULTADOS}

O Quadro 1, mostra alguns esportes nos quais o COI, e a agência mundial antidoping fiscalizam, visando a punição de atletas que usam substâncias ilegais, a fim de obter vantagens em relação aos seus adversários. 
Quadro 1. Diuréicos

\section{Esportes onde utilizam diuréticos ilícitos segundo agência mundial antidoping}

Boxe

Judô

Luta livre

Taekwendo

Canoagem

Karate

Fisiculturismo

Fonte: Agência mundial antidoping, Adaptado por Segati, 2015.

Os quadros 2 e 3 evidenciam os antiácidos e antidiarreicos encontrados com facilidade nas redes de farmácias, no território nacional e habitualmente utilizados por atletas de diversas modalidades.

Quadro 2. Fármacos antiácidos

\begin{tabular}{|l|l|l|}
\hline \multicolumn{2}{|c|}{ ANTIÁCIDOS } \\
\hline Aclorisan & ALCA luftal & Alrac \\
Asilone & Kolantyl & Mylantaplus \\
Leite de magnésia & Simecoplus & Gastrol \\
Bisuisan & Sonrisal & \\
\hline
\end{tabular}

Quadro 3. Fármacos antidiarreicos

\begin{tabular}{|l|l|l|}
\hline \multicolumn{3}{|c|}{ ANTIDIARREICOS } \\
\hline Colestase & Diasec & Imosec \\
Kaogama & Lomotil & Florax \\
Enterobion & Fura zolin & Floratil \\
\hline
\end{tabular}


O quadro 4 mostra os antiinflamatórios, de fácil acesso, utilizados por atletas de diversas modalidades

Quadro 4. Fármacos analgésicos e antiinflamatórios

\begin{tabular}{|l|l|l|}
\hline \multicolumn{2}{|c|}{ ANTIFLAMATORIOS } \\
\hline Advil & Biofenac & Artren \\
Artrosil & Benervan & Cataflam \\
Deltaflan & Feldene & Diclofenaco sódio \\
Cicladol & Fenaflan & Cetoprofeno \\
Flanax & Doretin & Butazona \\
Celebra & Cataflam d & Doriflan \\
Feldox & Nisulid & Proflan \\
Voltaren & Motrin & Scaflan \\
Nimesulida & & \\
\hline
\end{tabular}

No quadro 5 são paresentados os expectorantes utilizados por atletas, principalmente das modalidades de corrida e natação.

Quadro 5. Fármacos expectorantes

\begin{tabular}{|l|l|l|}
\hline \multicolumn{2}{|c|}{ EXPECTORANTES } \\
\hline Bisolvan & Fluimucil & Pulmonix \\
Silomat & Bisolvon & Subitan \\
Glicodin & Iodetal & Transpulmin \\
Benadryl & & \\
\hline
\end{tabular}
modalidades.

O quadro 6 evidencia os analgésicos e antipiréticos, comumente utilizados por atletas de várias

Quadro 6. Fármacos analgésicos e antipiréticos

\begin{tabular}{|l|l|l|}
\hline \multicolumn{3}{|c|}{ ANALGÉSICOS/ANTIPIRÉTICOS } \\
\hline Dipirona & Buscopan & Novalgina \\
Doran & Beralgin & Tylex \\
Tylenol & Paracetamol & Ponstan \\
\hline
\end{tabular}

\section{DISCUSSÃO}

Para a Comissão Médica do Comitê Olímpico Internacional 2000 (COI), a lista de substâncias proibidas para o atleta, contém cinco classes farmacológicas: estimulantes, narcótico-analgésicos, agentes anabolizantes, diuréticos e hormônios peptídicos (SILVEIRA; VAZ, 2016).

Os estimulantes: amineptina, amifenazol, anfetaminas, bromantano, carfedon, cocaína, efedrina, fencanfamina, mesocarbo, pentetrazol, pipradol, salbutamol e terbutalina. Os diuréticos: acetazolamida, 
bumetamida, clortalidona, ácido etacrínico, furosemida, hidroclorotiazida, manitol, mersalil, espironolactona, triantereno. Tais substâncias são utilizadas por atletas que desejam reduzir sua massa corporal em esportes que delimitem um valor limite de peso para cada categoria, sendo eles o boxe e as artes marciais mistas (MMA) (WEINECK, 2005).

Com relação a hidroclorotiazida (clorana) e espironolactona (aldactone) são diuréticos que são utilizados inibindo competitivamente a aldosterona dos rins, levando a excreção de sódio e água e a retenção de potássio (CAETANO, 2014). São alguns efeitos adversos, para quem utiliza os diuréticos: perda de peso, câimbras musculares, perda de potássio, o que causa,consequentemente diminuição da pressão sanguínea, distúrbios do ritmo cardíaco, redução da glicemia, alcalose sistêmica e aumento do ácido úrico.

Segundo Castanho, Fontes e Fernandes (2014) entre as substâncias que que estão em maior prevalência relacionada ao doping nos atletas são os diuréticos, sendo esses medicamentos estão de fácil acesso nas farmácias. Já os peptídeos, nos atletas, atuam na estimulação da produção do hormônio de crescimento, contribuindo para o fortalecimento e potência muscular. A dificuldade de aceitação do indivíduo em relação as suas limitações físicas leva o atleta a buscar alternativas no anseio de incrementar todas as possíveis formas de potencializar suas capacidades naturais (ZVEREVA et al., 2016).

De acordo com o comitê olímpico internacional, conjuntamente com a agência mundial de antidoping, existem fármacos permitidos para o atleta, nos casos em que há mal estar. Por exemplo, os esportistas de alto nível podem recorrer às substancias farmacológicas quando há sintomas de azia, queimação e dores estomacais. No entanto, o mesmo deve procurar orientação médica e se informar sobre os riscos que contém os medicamentos utilizados, para não ocorrer doping esportivo (ZOBOLI et al., 2016).

Conforme os antiácidos encontrados na tabela 2, o consumo desses medicamentos atuam na alterando o pH gástrico e urinário, e este tipo de medicamento está disponível em todas as formácias do Brasil inclusive no Sistema Único de Saúde (SUS) (SCHROETER et al., 2008). As substâncias que são proibidas em todos os momentos ou nas competições são frequentemente encontradas nos atletas, no entando, esses incidentes críticos causa desclassificação e oferece grande risco para a saúde (WHITAKER; BLACKHOUSE, 2016). O doping é geralmente considerado anti-desportivo e utilizado para criar vantagens injustas no esporte, tendo em vista a importância de cuidar e proteger e saúde e a integridade dos atletas, a prevenção da dopagem nos esportes de elite já é considerado uma prioridade das federações desportivas internacionais como forma de promover a saúde dos atletas (BLANK et al., 2016).

Os antidiarreicos podem ser utilizados como obstipantes, adsorventes, antiflatulentos e antimicrobianos, no entando é de ciência que a grande parte das diarréias é auto-limitante, não necessitando de medicamento para controle, pois a maioria é de origem viral (SILVA et al., 2013). Conforme pode-se observar na tabela 3 os principais antidiarreicos que são comercializados com frequência, portanto, deve-se orientar aos esportistas que é necessário nos quadros diarréicos a sua hidratação (PELOI et al., 2016).

Como em qualquer atividade ilegal, ou clandestina, existe dificuldade de fazer um acompanhamento do seu uso no tempo e em uma avaliação dos riscos que essas substâncias trazem para a saúde (MASSALDJIEVA; GUEORGUIEVA; MANTARKOV, 2010). O doping além de ser um comportamento ameaçador para a saúde, ele também corrompe a essência, valor e imagem do esporte (KONDRIC et al., 2011). Silva et al. (2013) enfatizaram que, no Brasil algumas substâncias que são compradas nas farmácias, sem o necessário controle para consumo e venda (SILVA; DANIELSKI; CZEPIELEWSKI, 2002)

No estudo de Rose et al. (2006) que teve por objetivo descrever a prevalência do uso de medicamentos e suplementos alimentares em atletas que participaram obrigatóriamente do controle de dopagem em um campeonato Sul-Americano. Participaram do estudo 234 atletas de 25 esportes distribuídos entre os 13 países participantes e 44\% dos atletas informaram a utilização de medicamentos até três dias antes da competição. Ao detalhar esses medicamentos, a maioria (24\%) foi antiinflamatório não esteróides, 15,9\% analgésicos, 4,3\% antibióticos, 3\% antigripais e 19,3\% de outros medicamentos. Esses dados corrobam com o presente estudo que os antiinflamatórios são os medicamentos que apresentam a maior variedade de tipos admistrados por atletas. 
Corrigan e Kazlauskas (2003) realizaram um estudo para analisar a incidencia de uso referido de medicamentos e suplementos alimentares nos atletas que participaram os Jogos Olímpicos de Sidney no ano de 2000, verificaram que os antiinflamatórios foram largamente administrados por atletas de várias modalidades, correspondendo a $25,6 \%$ do total de exames realizados do controle de doping.

Existe um excesso do uso de antiinflamatório e analgésico em diversas modalidades esportivas, que pode ocasionar eventual resultado analítico adverso no controle de doping por manupulação ou contaminação (ROSE et al., 2006). Alguns atletas estão conscientes dos riscos das substâncias, no entanto outros precisam de mais sensibilização e informação de que os medicamentos comprados nas farmácias podem atuar negativamente, sendo assim, os atletas podem ser desclassificados nas avaliações anti-doping realizadas nos campeonatos (AMA et al., 2003).

Os analgésicos alfaprofina, anileridina, dextromoramida, buprenorfina, dipipanona, metadona, morfina, pentazocina, petidina entre outros, são fármacos que estão disponíveis no dia-a-dia da comunidade esportista e que causa doping nas avaliações pré-jogos (MASCARENHAS, 2016). Os médicos precisam estar cientes de que, durante o tratamento dos atletas, certos medicamentos que não são ilegais para prescrever a comunidade em geral podem resultar na infração do atleta nas regras antidopagem. Medicamentos que não parecem ser óbivos para doping como insulina, probenicid, diuréticos, betabloqueadors e terbutalina precisam ser prescritos com cuidado (HUGHES, 2015).

Já os fármacos estimulantes como sulbutamol, terbutaline e salmeterol podem até ser utilizados sob a forma de aerosol e especificamente para prevenção e tratamento de asma e asma induzida pelo exercício, porém o atleta que utiliza esse tipo de fármaco deve ter realizado uma espirometria e uma carta médica para caracterizar a presença dessa complicação respiratória, caso contrário é considerado doping e o atleta é desclassificado (CAMPOS; BIAGIONI, 2001).

Al Ghobain et al. (2016) realizaram um estudo para estimar a prevalência e abordar os conhecimentos sobre substâncias entre os 1142 atletas, de 70 clubes, na Aráia Saudita. A prevalência do uso de substâncias proibidas foi de 4,3\%, sendo a principal razão a melhorara do desempenho (69\%). Muito mais da metade $(70 \%)$ dos atletas declarou ter ciência da punição contra o doping. Um dado interessante foi de que $65 \%$ dos atletas admitiram que recebem aconselhamento sobre tais substância proibidas e de medicamentos que estão disponíveis nas farmácias.

A esportivização da sociedade apresenta novos desafios, pelo fato de que o atleta está sendo elevado à posição de líder e sendo exemplo para a sociedade (RODEK et al., 2013). O seu nível no esporte e o corpo definido representa para a sociedade conteporânea qualidades positivas (KREMENIK et al., 2007). O atleta que utiliza esteroide ou outras substâncias ilegais ao se idealizar, cria-se um padrão inatingível para a sociedade, no entanto sua saúde pode estar comprometida (PETRÓCZI et al., 2015).

Segundo Almeida, Gutierrez e Gutierrez (2016) o doping é tão antigo quanto o esporte, e sempre que houver competição esportiva que tenha regras, haverá pessoas procurando encontrar a interpretação das regras que se beneficie ou facilmente tentando trapaciá-las. Os modelos comportamentais dos atletas são susceptíveis de traduzir para modelos comportamental de jovens influenciando as futuras percepções e comportamentos (ZVAN et al., 2016).

A mídia em geral tem divulgado os casos de doping no mundo, porém ainda existem poucas formas de ações diante do uso destas substâncias, a fim de promover informações e orientações para a população em geral em relação aos riscos. Nesse sentido, vale ressaltar que o profissional de saúde tem o papel de desmistificar os mitos sobre a atividade física, enfatizando que existe a maneira de desenvolvimento muscular sem o uso de tais substâncias ilegais (SANTOS et al., 2006).

\section{CONCLUSÕES}

Por meio desse estudo, pode ser observado que dentre as substâncias responsáveis pelo doping, as mais utilizadas são os estimulantes, analgégicos, diuréticos e antidiarreicos. E que esses medicamentos estão de fácil acesso nas farmácias para o consumo da sociedade, inclusive os atletas. 


\section{REFERÊNCIAS}

AL GHOBAIN, M. et al. Prevalence, knowledge and attitude of prohibited substances use (doping) among Saudi sport players. Substance Abuse Treatment, Prevention and Policy, vol.11, n. 1, p. 14-20, 2016.

ALMEIDA, M. B.; GUTIERREZ, D. M. \& GUTIERREZ, G. L. O doping e os Jogos Olímpicos: diferentes dimensões do fenômeno. Revista USP, n. 108, p. 77-86, 2016.

AMA, P. F. M. et al. Football and doping: study of African amateur footballers. British journal of sports medicine, vol. 37, n. 4, p. 307-310, 2003.

AQUINO NETO, F. R. O papel do atleta na sociedade e o controle de dopagem no esporte. Revista Brasileira de Medicina no Esporte. vol.7, n. 4. , p. 138-148, 2001.

BLANK, C. et al. Predictors of doping intentions, susceptibility, and behaviour of elite athletes: a metaanalytic review. SpringerPlus, vol. 5, n. 1, p. 1333-1347, 2016.

CAETANO, N. Guia de remédios, 12 edição 2014/2015.

CAMPOS, L. E. M. \& BIAGIONI, C. M. Efeito broncodilatador do salbutamol inalado através de espaçadores com e sem tratamento antiestático. J Pneumol, vol. 27, n. 5, p. 249-54, 2001.

CASTANHO, G. K. F.; FONTES, E. B. \& FERNANDES, P. T. O perigo da contaminação de suplementos alimentares com substâncias ilícitas para os praticantes de exercício físico e esporte. Conexões, vol. 12, n. 1, p. 161-180, 2014.

CORRIGAN, B. \& KAZLAUSKAS, R. Medication Use in Athletes Selected for Doping Control at the Sydney Olympics (2000). Clinical Journal of Sport Medicine, vol. 13, n. 1, p. 33-40, 2003.

FIGUEIREDO, V. C. et al. Cosmetic doping: the problems of intramuscular application of oils. Revista Brasileira de Medicina do Esporte, vol. 17, n. 1, p. 56-61, 2011.

HUGHES, D. The World Anti-Doping Code in sport. Aust Prescr, vol. 38, n. 5, p. 167-170, 2015.

KONDRIC, M. et al. Is there a danger for myopia in anti-doping education? Comparative analysis of substance use and misuse in Olympic racket J Relig Health 123 sports calls for a broader approach. Substance Abuse Treatment Prevention and Policy, vol. 6, n. 27, p. 1747-1759, 2011.

KREMENIK, M. et al. A Historical Timeline of Doping in the Olympics. Kawasaki Journal of Medical Welfare, vol. 12, n. 2, p. 69-83, 2007.

MARTINS, M. P. T. D. et al. Medicamentos de uso odontológico considerados proibidos pela Agência Mundial Anti-Doping (WADA). Coleção Pesquisa em Educação Física, vol. 12, n. 2, p. 95-102, 2013.

MASCARENHAS, M. A. Doping no esporte e a nandrolona: uma revisão. Ciência em MovimentoBiociências e Saúde, vol. 16, n. 33, p. 36-46, 2016.

MASSALDJIEVA, R.; GUEORGUIEVA, K. \& MANTARKOV, M. Psychological and psychiatric side effects of doping in sporting activities. Psychology \& Health, vol. 25, p. 271-272, 2010.

PELOI, K. et al. Utilização de planejamento fatorial para a determinação da capacidade antioxidante e doseamento de flavonoides totais em Verbena minutiflora Briq. ex Moldenke (gervai). Rev. Bras. Plantas Med, vol. 18, n. 1, p. 1-8, 2016.

PETRÓCZI, A. et al. A call for policy guidance on psychometric testing in doping control in sport. International Journal of Drug Policy, vol. 26, n. 11, p. 1130-1139, 2015. 
PRECIADO, Beatriz. Texto Yonqui: sexo, drogas e biopolítica.Madrid, Espasa-Calpe, 2008.

RODEK, J. et al. Differential analysis of the doping behaviour templates in three types of sports. Collegium Antropologicum, vol. 37, p. 211-217, 2013.

ROSE, E. H. et al. Referred use of medication and dietary supplements in athletes selected for doping control in the South-American Games. Revista Brasileira de Medicina do Esporte, vol. 12, n. 5 p. 239-242, 2006.

SANTOS, A. F. et al. Anabolizantes: conceitos segundo praticantes de musculação em Aracaju (SE). Psicologia em Estudo, vol. 11, n. 2, p. 371-380, 2006.

SCHROETER, G. et al. Estudo de utilização de anti-ulcerosos na população idosa de Porto Alegre, RS, Brasil. Rev HCPA, vol. 28, n. 2, p. 89-95, 2008.

SILVA, G. M. S. et al. Análise da automedicação no município de Vassouras-RJ. Infarma-Ciências Farmacêuticas, vol. 17, n. 5, p. 59-62, 2013.

SILVA, P. R. P.; DANIELSKI, R. \& CZEPIELEWSKI, M. A. Esteróides anabolizantes no esporte. Revista Brasileira de Medicina do Esporte, vol. 8, n. 6, p.235-246, 2002.

SILVA, I.; MARCELINO, K.; GONZALEZ, R. O uso do doping no esporte: uma revisão de literatura. EFDeportes, vol. 180, n. 18, p. 1-7 2013.

SILVEIRA, V. T. \& VAZ, A. F. Doping e controle de feminilidade no esporte. Cadernos Pagu, vol. 42, p. 447-475, 2016.

WEINECK, J. Biologia do esporte. São Paulo: Manole, 2005.

WHITAKER, L. \& BACKHOUSE, S. H. Doping in sport: An analysis of sanctioned UK rugby union players between 2009 and 2015. Journal of Sports Sciences, vol. 32, n. 4, p. 1-7, 2016.

ZOBOLI, F. et al. O corpo híbrido: análise midiática da participação do atleta Oscar Pistorius no Mundial de Atletismo de 2011. Revista Brasileira de Ciências do Esporte, vol. 38, n. 1, p. 26-33, 2016.

ZVAN, M. et al. Gender-and Sport-Specific Associations Between Religiousness and Doping Behavior in High-Level Team Sports. Journal of religion and health, vol. 11, p. 1-13, 2016.

ZVEREVA, I. et al. Comparison of various in vitro model systems of the metabolism of synthetic doping peptides: proteolytic enzymes, human blood serum, liver and kidney microsomes and liver S9 fraction. Journal of Proteomics vol. 16, n. 3, p. 391-398, 2016. 